\title{
Ku86 exists as both a full-length and a protease-sensitive natural variant in multiple myeloma cells Charles A Gullo*1,2, Feng Ge ${ }^{2}$, Geraline Cow ${ }^{1,2}$ and Gerrard Teoh ${ }^{2,3}$
}

\begin{abstract}
Address: ${ }^{1}$ Department of Clinical Research (DCR), Cancer Immunology Laboratory, Singapore General Hospital (SGH), Outram Road, Singapore 169608, Singapore, ${ }^{2}$ Multiple Myeloma Research Laboratory (MMRL), Singapore Health Services Pte Ltd (SingHealth), 7 Hospital Drive, Block A \#02-05, Singapore 169611, Singapore and ${ }^{3}$ Department of Hematology, SGH, Outram Road, Singapore 169608, Singapore
\end{abstract}

Email: Charles A Gullo* - charles.gullo@sgh.com.sg; Feng Ge - frankge001@hotmail.com; Geraline Cow - gcow@jjisg.jnj.com; Gerrard Teoh - ghk_teoh@parkway.sg

* Corresponding author

Published: 29 April 2008

Cancer Cell International 2008, 8:4 doi:10.1186/1475-2867-8-4

This article is available from: http://www.cancerci.com/content/8/l/4

(c) 2008 Gullo et al; licensee BioMed Central Ltd.

This is an Open Access article distributed under the terms of the Creative Commons Attribution License (http://creativecommons.org/licenses/by/2.0), which permits unrestricted use, distribution, and reproduction in any medium, provided the original work is properly cited.

\begin{abstract}
Background: Truncated variants of Ku86 protein have previously been detected in $86 \%$ to $100 \%$ of freshly isolated patient multiple myeloma (MM) cells. Since, the Ku70/Ku86 heterodimer functions as the regulatory subunit of the DNA repair enzyme, DNA-dependent protein kinase, we have been interested in the altered expression and function of Ku86 variant (Ku86v) proteins in genome maintenance of MM.
\end{abstract}

Results: Although, a number of studies have suggested that truncated forms of Ku proteins could be artificially generated by proteolytic degradation in vitro in human lymphocytes, we now show using whole cell immunoblotting that the RPMI-8226 and SGH-MM5 human MM cell lines consistently express full-length Ku86 as well as a $69-\mathrm{kDa}$ Ku86v; a C-terminus truncated $69-\mathrm{kDa}$ variant Ku86 protein. In contrast, Ku86v proteins were not detected in the freshly isolated lymphocytes as was previously reported. Data also indicates that the Ku86v was not generated as a result of carbohydrate modification but that serine proteases may act on the full-length form of the protein.

Conclusion: These data confirm that MM cells contain bona fide Ku86v proteins that were generated intracellularly by a post-transcriptional mechanism, which required proteolytic processing.

\section{Introduction}

Ku80 and Ku70 are two important related family members involved in the facilitation of DNA double strand break repair (DSBR) in association with the DNA repair enzyme, the catalytic subunit of DNA-dependent protein kinase catalytic (DNA-PKcs), XRCC4, DNA ligase IV and a host of other enzymes. Although present in most cells, Ku 86 has been extensively studied in B and T cells due to its proposed role in the CD40-induced immunoglobulin
(Ig) class switch recombination (CSR) and V(D)J lymphocyte antigen recognition/recombination events, both of which generate transient DNA double-strand breaks. The importance of this protein in lymphocyte development was most notable in Ku86 knockout mice, which failed to develop mature lymphocytes [1]. There has also been a strong association with Ku-dependent DNA DSBR and/or protection from ionizing irradiation-induced DNA damage [2-6]. Besides its well known role in DNA repair, 
numerous reports have implicated Ku proteins in numerous other cellular processes, including the maintenance of telomere length, regulation of G2 and M phases of the cell cycle, regulation of apoptosis and specific gene transcription, and regulation of heat shock-induced responses $[7,8]$.

Although Ku86 and Ku70 are predominantly localized to the nucleus and the nuclear matrix, it has been found in other subcellular compartments including the cytoplasm [9] and cell membranes of numerous cell types [10,11]. The identification of $\mathrm{Ku}$ proteins in various compartments of the cell has led to the identification of putative novel functions of both Ku86 and Ku70. For example, in multiple myeloma (MM) cells, CD40-induced Ku86 surface expression resulted in increased cellular adhesion to fibronectin and bone marrow stromal cells [12] Other reports indicate that $\mathrm{Ku} 70 / \mathrm{Ku} 86$ is found in the cytoplasm during mitosis and it returns to the nucleus as the cell enters the G1 phase of the cell cycle $[13,14]$. Finally, in colonic tumor cells, translocation of Ku86 from the cytoplasm to the nucleus occurs via interactions with a growth inhibitory tetradecapeptide and thus, Ku86 acts as a putative somatostatin receptor [15]. Therefore, location of Ku86 and other members of the DNA repair machinery in various compartments of mammalian cells may lead to numerous downstream functional consequences.

There have been a number of reports that indicate Ku86 exists in two forms, an $86 \mathrm{kDa}$ full-length form and a Cterminal truncated variant form of approximately $69-\mathrm{kDa}$, in $\mathrm{B}$ cells from the peripheral blood (PB) [16], the acute promyelocytic leukemia (APL) cell line HL-60 [17], MM cells [5], as well as senescent fibroblasts [18]. It is unlikely that the variant protein is a product of alternative splicing of the Ku86 full length transcripts since shorter mRNAs have not been found by northern blot analysis [16,17]. Consistent with these findings, a 69-kDa variant of Ku86 was also found in the mitochondria of mammalian cells [19]. Furthermore, in the above reports, the variant of Ku86 was still able to bind DNA and associate with Ku70 consistent with the retention of the domains that are associated with those functions. Therefore, it is currently thought that variants of Ku86 are formed as a result of post-translational modification. It is the nature of this modification, which has resulted in some controversial issues regarding the physiological existence of this variant. Several recent studies have suggested that the Ku86 variant seen in lymphocytes may be due to cleavage by proteases induced during biochemical isolation [20-22]. Considering the increased amount of genomic instability seen in MM, the disregulated CD40/interleukin-4 (IL-4) pathway in $\mathrm{MM}$ cells [23], and the role of $\mathrm{Ku}$ in DNA DSBR and non-homologous end-joining (NHEJ), we investigated the presence of Ku86 and its variants in MM cells, and compared them to Tlymphocytes and other cell lines. We found that unlike human $\mathrm{T}$ lymphocytes, the detection of 69-kDa Ku86 (Ku86v-N) variant is not likely due to in vitro generated protease cleavage. Moreover, we demonstrate that the full-length, as well as the truncated form of Ku86 are found in the nucleus, membrane and cytosolic fractions of resting and CD40-stimulated MM cells. Finally, we show that intracellular protease inhibition can prevent the appearance of the Ku86 variant and that the protease responsible is likely to be a serine protease. The implications for these findings are discussed.

\section{Methods \\ Cell culture}

RPMI 8226 MM, CESS Epstein-Barr virus (EBV)-transformed normal B cells, K562 chronic myeloid leukemia (CML), and HL-60 APL human cell lines were all purchased from the American Type Culture Collection (ATCC, Rockville, MD). The EBV-negative SGH-MM5 human MM cell line (CD10+ CD19- CD20- CD38+ CD40+ CD45+ CD56+ CD138+) was developed in our laboratory under the Singapore General Hospital (SGH) Institutional Review Board (IRB) good research practice guidelines, from a patient with MM using a modified Dexter-type long-term tissue culture system, which was previously described [23]. All cell lines were cultured in RPMI 1640 medium (Invitrogen, Gibco, Grand Island, NY) supplemented with $10 \%$ fetal calf serum (FCS) at $37^{\circ} \mathrm{C}$ and $5 \% \mathrm{CO}_{2}$. Normal PB human T cells were isolated from buffy coat preparations from healthy donors (after informed consents were obtained) using Ficoll Hypaque density gradient centrifugation and CD3 positive magnetic bead immunoseparation (MACS columns, Miltenyi Biotec, GmbH, Gladbach, Germany). For CD40 stimulation conditions, MM cells were optimally stimulated with soluble CD40 ligand (sCD40L) (Peprotech Inc., Rocky Hill, NJ) for 4 hrs at $5.0 \mathrm{ng} / \mathrm{mL}$ [23].

\section{Cell extract preparation}

Fresh whole cell extracts

Cells were washed in phosphate buffered saline (PBS), pelleted, resuspended in $2 \times$ sodium dodecyl-sulfate (SDS) loading buffer (120 mM Tris $\mathrm{HCl} \mathrm{pH} \mathrm{7.0,4 \%} \mathrm{SDS,} 720$ $\mathrm{mM}$ 2-mercaptoethanol (2-ME), 0.01\% bromophenol blue and 20\% glycerol), and directly boiled for 10 mins to inactivate proteases [22] as previously described. Whole cell extracts were then recovered by centrifugation at $12,000 \mathrm{~g}$ for $10 \mathrm{mins}$ and loaded equally and immediately onto SDS polyacrylamide gel electrophoresis (PAGE) gels.

\section{Conventional whole cell extracts}

Cells were lysed in EBC1 lysis buffer (50 mM Tris $\mathrm{HCl}, \mathrm{pH}$ 8.0, $150 \mathrm{mM} \mathrm{NaCl}, 0.1 \% \mathrm{NP}-40,50 \mathrm{mM} \mathrm{NaF}, 1 \mathrm{mM}$ $\mathrm{Na}_{3} \mathrm{VO}_{4}, \quad 0.5 \mu \mathrm{g} / \mathrm{ml}$ phenylmethylsulphonylfluoride (PMSF), and 1 freshly added tablet of protease inhibitor 
mixture per $50 \mathrm{ml}$ of buffer (Complete $\mathrm{e}^{\mathrm{TM}}$ protease inhibitor tablets; Boehringer Mannheim, Roche Diagnostics $\mathrm{GmbH}$, Mannheim, Germany). The mixture was then boiled in SDS sample buffer for 3 to 5 mins before loading onto SDS-PAGE gels.

\section{Conventional cytosolic protein extracts}

Cells were first washed in PBS and lysed in 10 volumes of the lysis buffer $\left(10 \mathrm{mM}\right.$ Tris $\mathrm{HCl} \mathrm{pH}$ 7.6, $1.5 \mathrm{mM} \mathrm{MgCl}_{2}$, $10 \mathrm{mM} \mathrm{KCl}, 0.5 \% \mathrm{NP}-40,1 \mathrm{mM}$ dithiotretinol (DTT), and 1 freshly added Complete ${ }^{\mathrm{TM}}$ protease inhibitor tablet). Cytosolic protein extracts were recovered by centrifugation at $1,000 \mathrm{~g}$ for 15 mins [20].

\section{Conventional nuclear protein extracts}

From the above pellet, cell nuclei were next lysed in 5 volumes of a low-salt buffer (20 mM HEPES pH 7.9, 25\% glycerol, $1.5 \mathrm{mM} \mathrm{MgCl}_{2}, 10 \mathrm{mM} \mathrm{KCl}, 0.5 \mathrm{mM}$ ethylenediaminetetraacetic acid (EDTA), and 1 freshly added Complete $^{\mathrm{TM}}$ protease inhibitor tablet). Next, an equal volume of a high-salt buffer (i.e. low-salt buffer plus $0.8 \mathrm{M} \mathrm{NaCl}$ ) was added, and the mixture left to stand on ice for 15 mins. [20]. Nuclear protein extracts were recovered by centrifugation at $16,000 \mathrm{~g}$ for 15 mins.

\section{Membrane protein extracts}

Cells were washed three times with ice-cold PBS, centrifuged at $3,000 \mathrm{~g}$ for $5 \mathrm{mins}$, and the pellet resuspended in $0.5 \mathrm{ml}$ of TEM A lysis buffer ( $20 \mathrm{mM}$ Tris $\mathrm{HCl} \mathrm{pH}$ 8.0, 0.5 mM EDTA, $0.5 \mathrm{mM}$ EGTA, $10 \mathrm{mM}$ 2-ME, and 1 freshly added Complete ${ }^{\mathrm{TM}}$ protease inhibitor tablet), incubated on ice for 5 mins, and then sonicated. Membrane protein extracts were obtained by double sequential centrifugation of the lysis mixture, first at $1,000 \mathrm{~g}$ for 5 mins, then at $100,000 \mathrm{~g}$ for $30 \mathrm{mins}$ for $250 \mu \mathrm{L}$ of the supernatant. For all the assays above, Bradford's assay (Bio-Rad, Hercules, $\mathrm{CA}$ ) was used to quantify protein concentrations in all samples.

\section{Western immunoblotting}

Cell lysates ( $20.0 \mu \mathrm{g}$ of protein/sample) were first resolved on a $12.5 \%$ SDS-PAGE gel, transferred onto polyvinylidene difluoride (PVDF) membranes (Millipore Corporation, Billerica, MA) and then blocked using Tris buffered saline Tween-20 (TBST) buffer containing 5\% non-fat milk. Membranes were next hybridized overnight in the cold room using various murine monoclonal antibodies $(\mathrm{mAb})$ - i.e. S10B1 anti-Ku86 N-terminus (amino acid (aa) residues 8-221; NeoMarkers, Fremont, CA); antiheavy chain of the human major histocompatibility complex (MHC) mAb (clone 22.63.4, Accurate Chemical and Scientific Co., Westbuty, NY; a kind gift from P. Macary, from the National University of Singapore); and anti-actin (Santa Cruz Biotechnology, Santa Cruz, CA) mAbs; washed three times in ice cold TBS-T; and then incubated with horseradish peroxidase (hrp) conjugated anti-mouse IgG mAb (1:2,000; Santa Cruz) for $1 \mathrm{hr}$. The reaction was detected using the ChemiGlow chemiluminescence reagents (Alpha Innotech, San Leandra, CA). Image spot densitometry was performed on the Alpha Imager (Alpha Innotech).

\section{Electrophoretic mobility shift assay (EMSA)}

Two 25-mer oligonucleotides; 5'-ACTTGATTAGTTACGTAACGTTATG-3' and 5'-CATAACGTTACGTAACTAATCAAGT-3', with or without biotin labels at the $5^{\prime}$ ends (1 ${ }^{\text {st }}$ Base Pte Ltd., Singapore), were first annealed together (see Pierce Technical Resource, TR0045.0, Pierce, Rockford, IL). Standard EMSA reactions (Lightshift Chemiluminescent EMSA kit, Pierce) incorporated $4.0 \mu \mathrm{g}$ of cell extract and $20.0 \mathrm{fmol}$ of biotin end-labeled DNA in a $20.0 \mu \mathrm{L}$ volume binding reaction in the presence of $2.5 \%$ glycerol, 5 $\mathrm{mM} \mathrm{MgCl} 2,50 \mathrm{ng} / \mu \mathrm{L}$ of poly $(\mathrm{dI} \cdot \mathrm{dC})$, and $0.05 \% \mathrm{NP}-40$. Unlabeled target DNA (4.0 pmol) was added per $20.0 \mu \mathrm{L}$ of binding reaction where indicated. Reactions were incubated at room temperature for $30 \mathrm{mins}$ and terminated by adding $2.0 \mu \mathrm{L}$ of $10 \times$ loading buffer $(0.2 \%(\mathrm{w} / \mathrm{v})$ bromophenol blue and $0.2 \%$ xylene cyanol containing $10 \%(\mathrm{v} / \mathrm{v})$ glycerol). Assays were loaded onto native $5 \%$ polyacrylamide gels that were pre-electrophoresed for 60 mins in $0.5 \times$ Tris borate/EDTA buffer, resolved at $100 \mathrm{~V}$, and transferred onto nylon membranes (Hybond ${ }^{\mathrm{TM}}-\mathrm{N}^{+}$, Amersham) in $0.5 \times$ Tris borate/EDTA buffer at $100 \mathrm{~V}$ for 30 mins. DNA was cross-linked $\left(120 \mathrm{~mJ} / \mathrm{cm}^{2}\right)$ and detected using hrp-conjugated streptavidin chemiluminescence. Image spot densitometry was performed on the Alpha Imager (Alpha Innotech).

\section{Endoglycosidase $\boldsymbol{H}$ (EndoH) digestion}

Endoglycosidase $\mathrm{H}$ resistance was assayed using the EndoH digestion system (New England Biolabs, Ipswich, $\mathrm{MA}$ ) and performed according to the manufacturer's recommendations. Briefly, $30.0 \mu \mathrm{g}$ of whole cell extracts were denatured at $100^{\circ} \mathrm{C}$ for 10 mins using $1 \times$ glycoprotein denaturing buffer, followed by addition of $1 \times$ G5 buffer and $1.0 \mu \mathrm{L}$ (500 units) of EndoH. The reaction mix was incubated at $37^{\circ} \mathrm{C}$; and at various time points, aliquots were removed and resolved in a $12.5 \%$ SDS-PAGE gel for carbohydrate $(\mathrm{CHO})$ release.

\section{Intracellular inhibition of protease digestion}

In order to inhibit intracellular protease activity, $5 \times 10^{6}$ cells/sample were treated with: Complete ${ }^{\mathrm{TM}}$ protease inhibitor tablets; either $1 \times(1$ tablet for every $50 \mathrm{~mL}$ of media) or $2 \times$ ( 2 tablets for every $50 \mathrm{~mL}$ of media); or treated with antipain $(2.0 \mu \mathrm{g} / \mathrm{mL})$ plus leupeptin $(2.0 \mu \mathrm{g} /$ $\mathrm{mL}$ ) (both from Sigma-Aldrich, St Louis, MO, USA) for cysteine protease inhibition; or aprotinin $(2.0 \mu \mathrm{g} / \mathrm{mL})$ plus PMSF $(100 \mu \mathrm{g} / \mathrm{mL})$ (both from Sigma-Aldrich) for serine protease inhibition; for to $24 \mathrm{hrs}$. Cell viability was 
assessed by standard trypan-blue exclusion assays. Image spot densitometry was performed on the Alpha Imager (Alpha Innotech).

\section{Cloning of Human Ku86 from RPMI cells}

Full-length $2.4 \mathrm{~kb}$ Ku 86 cDNA was obtained from total RNA of RPMI 8226 MM cell lines by RT-PCR (Qiagen Inc., Valencia CA, USA). The primers used to amplify the Ku 86 message were forward primer: 5' -TGTATGGACGTGGGCTTTACCAT-3' and reverse primer: 5' -TCCACAGAGAATTAGATGATCCGCC-3'. Purified Ku86 cDNA (2.4 $\mathrm{kb}$ ) was then cloned into Topo-vector (Invitrogen) and transformed into E. coli. The cloned Ku86 gene was fully sequenced to confirm the insertion of full length $2.4 \mathrm{~kb}$ Ku86 into the clone without any detected mutations (BigDye $^{\mathrm{TM}}$ Cycle Sequencing Kit, Applied Biosystems, Foster City, CA USA). In order to subclone the construct into an mammalian expression system, two restriction enzyme sites were engineered to the ends of cloned Ku86 gene (HindIII at $5^{\prime}$ end and XbaI at 3 ' end) by PCR of the clone using high fidelity PWO SuperYield ${ }^{\mathrm{TM}}$ DNA polymerase (Roche Diagnostics) and the following oligo's: Forward oligo:

5 'ATTAAAGCTTCCGGCAACATGGTGCGGTCGGGGAATA AGGCAGCTGTTGTGCTGTGTATGGACGTGGGC-3' and Reverse oligo: 5'ATTATCTAGACTTATCATGTCCAATA AATC-3'. The engineered Ku86 was then subcloned into the transient mammalian expression vector, pcDNA3.1/ myc-His B (Invitrogen). The purified plasmid (Ku86+ pcDNA3.1/myc-His B) was then transfected into mammalian cell line (COS-7) for transient expression of Ku86 recombinant protein, using the Lipofectamine $2000^{\mathrm{TM}}$ reagent (Invitrogen). Finally, the Ku86 recombinant proteins were purified using ProBond ${ }^{\mathrm{TM}}$ Nickel-Chelating Resin column (Invitrogen) and detected using western Immunblotting with anti-myc-HRP (Invitrogen) and/or anti-Ku86 antibody (Neomarker).

\section{Trypsin digestion of recombinant human Ku86 (rhKu86) protein}

Full-length rhKu86 was first expressed and purified from COS cells and digested ( $6.5 \mu \mathrm{g} / \mathrm{sample}$ or $13.0 \mu \mathrm{g} / \mathrm{sample})$ using trypsin $(0.065 \mu \mathrm{g}$ of Trypsin Gold/reaction, Promega Corp. Madison, WI); at 100:1 protease:protein ratio, in $50 \mathrm{nM}$ acetic acid, $\mathrm{pH} 8.0$, and $37^{\circ} \mathrm{C}$, as recommended at by the manufacturer (Promega Technical Bulletin, 309). The reaction was stopped by rapid freezing on ice, and analyzed using SDS-PAGE and western immunoblotting.

\section{Results and Discussion Ku86 truncation is not the result of in vitro generated proteolysis in MM cell lines}

Although a number of studies have characterized a 69$\mathrm{kDa}$ to $70-\mathrm{kDa}$ truncated variant of Ku 86 in vitro, a few recent studies have suggested that this variant may be the result of in vitro induced proteolysis during storage, handling and lysis of B or T lymphocytes [21,22]. In this present study, an SDS-PAGE whole cell lysis procedure, in which all proteolytic activity is inhibited during isolation, was used to demonstrate that RPMI 8226 and SGH-MM5 MM cells (Fig. 1A, lanes 5 and 6) contain a 69-kDa N-terminus Ku86v despite the omission of the protein extraction steps and minimization of protease action. In contrast, and in agreement with prior findings, human $\mathrm{T}$ cells (samples from patient 1; Fig. 1A, lane 1) freshly isolated from the PB did not display altered forms of Ku86. Furthermore, CESS EBV-transformed B cell and K562 CML cell lines (Fig. 1A, lanes 2 and 3), which are known to lack the expression of the $69-\mathrm{kDa}$ variant of Ku86, served as negative controls; and the HL-60 APL cell line (Fig. 1A, lane 4), which is known to contain the $69-\mathrm{kDa}$ form of Ku86v, was used as a positive control for this assay. These data suggest that the $69-\mathrm{kDa}$ form of Ku86v is generated in vivo, and is not likely to be an in vitro artifact, in human MM cell lines.

In order to demonstrate in vitro proteolysis of Ku86, we next analyzed protein extracts prepared using conventional methods from previously frozen and stored cells (Fig. 1B). Specifically, human $\mathrm{T}$ cells (samples from patients 2 and 3), CESS and the K562 cell lines, that lack 69-kDa Ku86v expression (Fig. 1B, lanes 1 to 4); were compared with the HL-60 cell line, which is known to express 69-kDa Ku86v, RPMI 8226, and SGH-MM5 MM cell lines (Fig. 1B, lanes 5 to 7). In this experiment, both human T cells, as well as the CESS and K562 cell lines not only contained 69-kDa Ku86v, but also various other fragments of Ku86. Moreover, even HL-60, RPMI 8226 and SGH-MM5 cell lines, that constitutively express $69-\mathrm{kDa}$ Ku86v, also contained numerous Ku86 fragments. These data suggest that freezing and storage of cells leads to extensive in vitro proteolysis of cellular proteins. Furthermore, whole cell extracts from the RPMI 8226 cell line, which were made in a protease-free extraction buffer, i.e. either extraction buffer plus $1 \times$ Complete $^{\mathrm{TM}}$ tablet (Roche Diagnostics) and $1 \times$ PMSF, or extraction buffer plus $2 \times$ Complete $^{\mathrm{TM}}$ tablets and $2 \times$ PMSF, demonstrated no change in the expression of the Ku86 variant or its full-length form (data not shown). Collectively, these data confirm that although proteases released during isolation procedures can lead to extensive Ku86 degradation in vitro, truncated forms of Ku86 in RPMI 8226 and SGH-MM5 MM cell lines are more likely to have been generated in vivo and constitutively.

\section{The 69-kDa Ku86v in MM cell lines are present in the cytosolic, nuclear and membrane fractions and binds DNA} Since CD40 activation of MM cell lines results in the membrane expression of Ku86 in MM cells $[6,12,12]$, we 


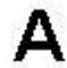

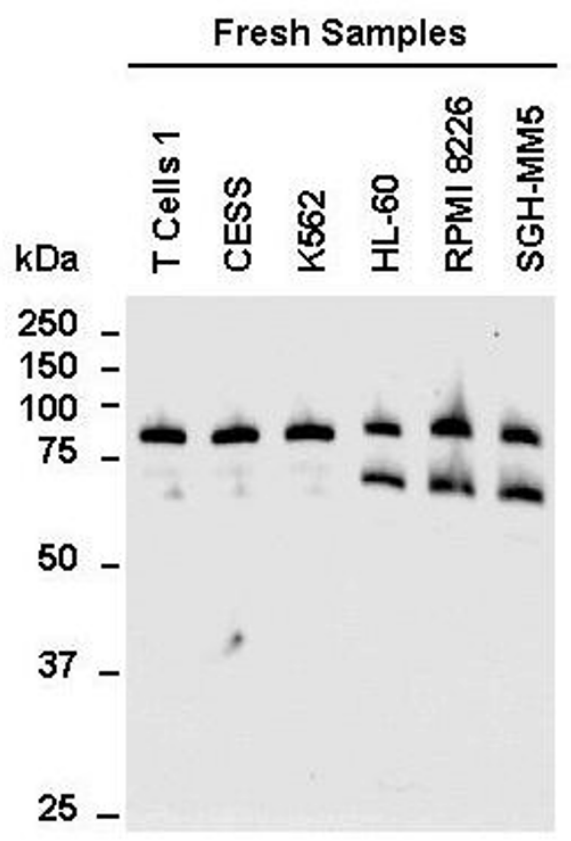

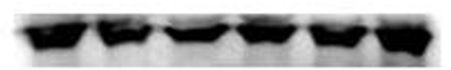

B

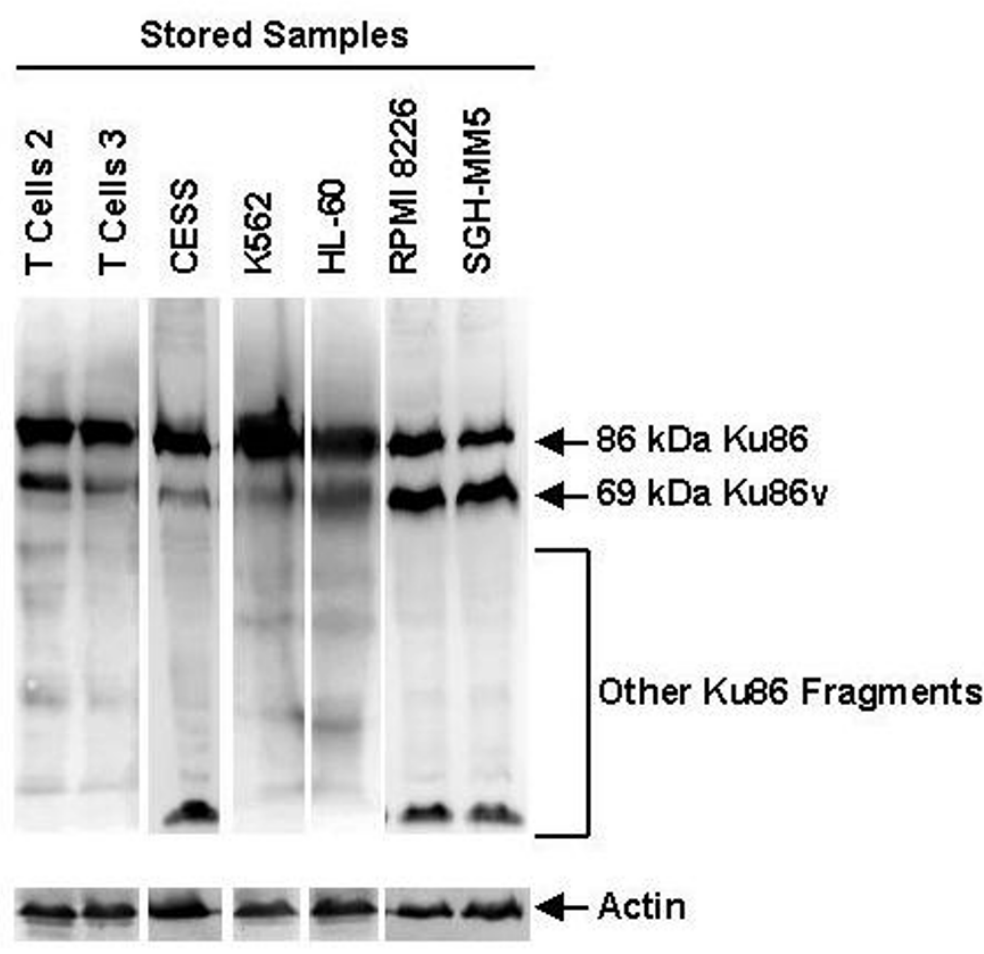

Figure I

Ku86 truncation is not the result of in vitro generated proteolysis in human MM cell lines. Immediate whole cell lysis (5.0 × $10^{6}$ cells/sample) was performed on freshly-obtained human PB T cells (sample from patient I), CESS, K562, HL60, and RPMI 8226 and SGH-MM5 MM cell lines using a denaturing and reducing gel-loading buffer $\left(95^{\circ} \mathrm{C}\right.$ for 10 mins) (A). Cell extracts were also prepared using conventional methods from previously frozen and stored human PB T cells (samples from patients 2 and 3), K562 CML, and HL60, and RPMI 8226 and SGH-MM5 MM cell lines (B). Cell lysates (20.0 $\mu$ g/sample) were resolved on a $12.5 \%$ SDS-PAGE gel, transferred onto PVDF membranes, and probed with SIOBI anti-Ku86 mAb, which recognizes the $\mathrm{N}$-terminus of Ku86. Membranes were stripped and re-probed using anti-actin mAb (control) to confirm equal protein loading. Experiments were performed in triplicate.

also investigated the distribution of $69-\mathrm{kDa} \mathrm{Ku} 86 \mathrm{v}$ in various subcellular locations, i.e. cytosol, nucleus and cell membrane, relative to CD40 triggering. As can be seen in Fig. 2A, 69-kDa Ku86v is present in all subfractions but is at higher (2.5-fold) levels in the cytosol after CD40 triggering of the RPMI $8226 \mathrm{MM}$ cell line. In order to define a functional role for this observation, we analyzed the DNA-binding characteristics of Ku86 and Ku86v to a known 25-bp Ku86 binding DNA oligonucleotide using EMSAs (Figs. 2B and 2C) [16,22], in CD40-triggered RPMI $8226 \mathrm{MM}$ cells in various subcellular fractions. We demonstrate binding of DNA to both $86-\mathrm{kDa}$ Ku 86 (band position I) as well as $69-\mathrm{kDa} \mathrm{Ku} 86 \mathrm{v}$ (band position II); confirming the presence of these proteins in the RPMI $8226 \mathrm{MM}$ cell line. In contrast, only full-length Ku86 was found in the negative control CESS cells. Similar results were obtained for the SGH-MM5 MM cell line (data not shown). Interestingly, no other bands are detected suggesting that if other forms of Ku86 exist they do not bind DNA. Moreover, cold competitor DNA was used to confirm specificity of the 25-bp oligonucleotide for Ku86 binding (Fig. 2C). Since the DNA binding domain of Ku 86 is located in the N-terminus and is preserved in both full-length Ku86 as well as the 69-kDa Ku86v, our data not only confirms the presence of truncated Ku86v, but also suggests a functional role for Ku86v.

Surprisingly, triggering of MM cells via CD40 had no effect on the amount of $86-\mathrm{kDa} \mathrm{Ku} 86$ protein bound to DNA in all cellular subfractions (Fig. 2B, band position I) isolated from RPMI 8226 cells and well as SGH-MM5 MM cell line (data not shown). By contrast, binding of $69-\mathrm{kDa}$ 


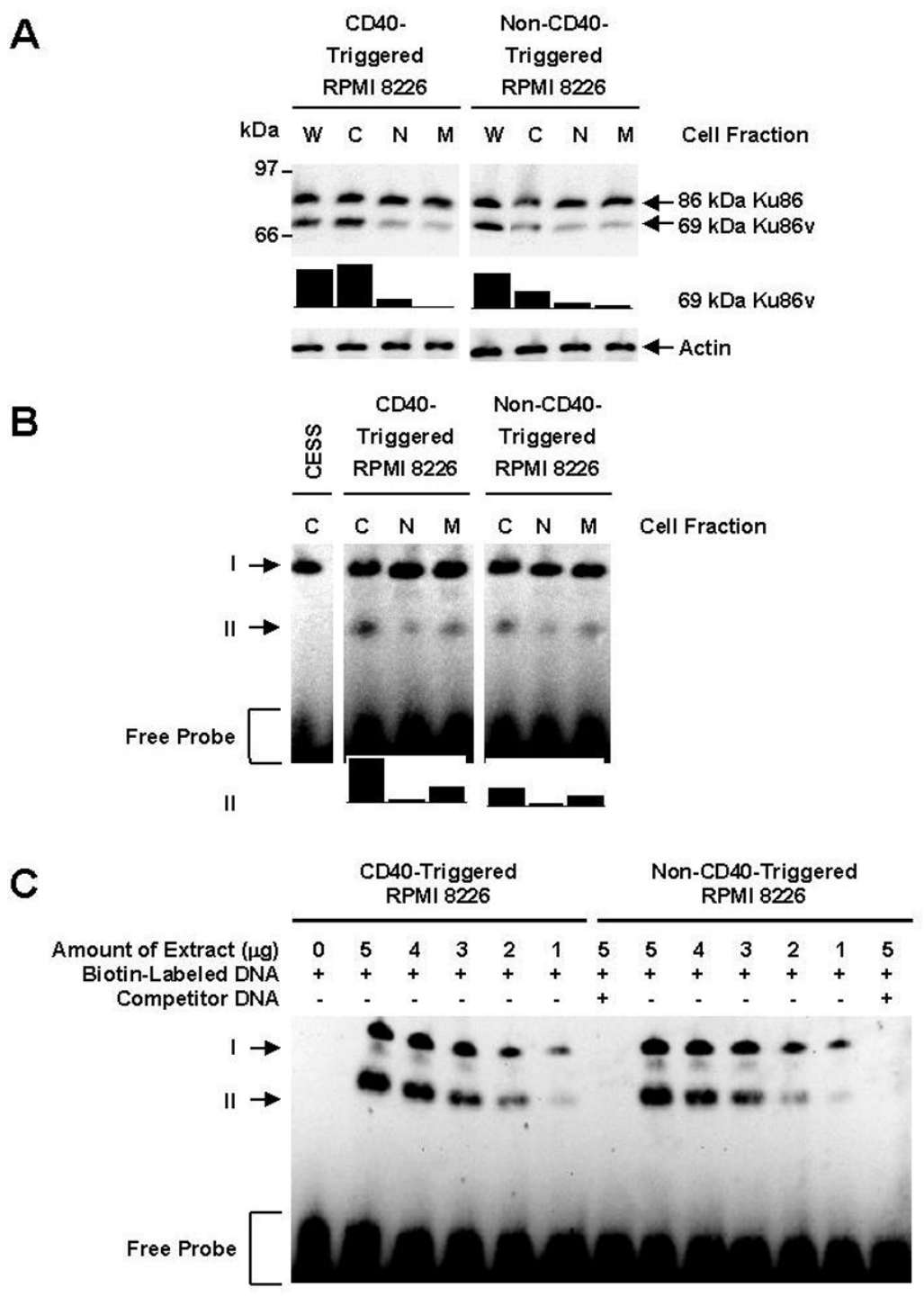

\section{Figure 2}

The 69-kDa Ku86v in MM cell lines is present in the cytosolic, nuclear and membrane fractions and binds DNA. Having determined that MM cell lines constitutively express 69-kDa Ku86v, we next studied the subcellular location of Ku86v. Moreover, since CD40 triggering induces expression of $86-\mathrm{kDa}$ Ku86 on the cell membrane of MM cells, we also investigated whether CD40 triggering affected the subcellular location Ku86v. Fresh whole cell (W), cytosolic (C), nuclear (N) and membrane $(M)$ cell lysate fractions were obtained from sCD40L-triggered $(5.0 \mu \mathrm{g} / \mathrm{mL}$ for $4 \mathrm{hrs})$ and resting RPMI $8226 \mathrm{MM}$ cells, and subjected to normal SDS-PAGE (A). Full-length and variant forms of Ku86 were detected by western immunoblotting using SIOBI anti-Ku86 mAb. Membranes were stripped and re-probed using anti-actin mAb (control) to confirm equal protein loading. Relative expression of 69-kDa Ku86v (normalized to weakest band) was determined using image densitometry and expressed in bar chart format. The presence of Ku86/Ku86v protein-DNA complexes were next detected using EMSA (B and C). Cytosolic $(C)$, nuclear $(N)$ or membrane $(M)$ protein extracts $(4.0 \mu \mathrm{g} /$ sample) were first obtained from CESS (negative control), CD40-triggered $(5.0 \mu \mathrm{g} / \mathrm{mL}$ sCD40L for $4 \mathrm{hrs})$ or non-CD40-triggered RPMI $8226 \mathrm{MM}$ cell lines. Non-competitive binding of Ku86/Ku86v to DNA (B) was detected using a specific biotin end-labeled DNA probe (20.0 fmol/sample), native PAGE, and hrp-conjugated streptavidin chemiluminescence imaging. Full-length Ku86-DNA complexes are found at position I, whereas DNA complexes with the truncation variant of Ku86 are found at position II. Relative expression of 69-kDa Ku86v-DNA complexes (normalized to weakest band) was determined using image densitometry. To confirm the specificity of DNA binding, a competitive assay $(\mathrm{C})$, in which a variable amount of cell lysate (up to $5.0 \mu \mathrm{g} / \mathrm{sample}$ ) was mixed with a fixed amount (4.0 pmol/ sample) of non-biotin-labeled DNA, was also performed in the same fashion. All experiments were repeated with the SGHMM5 MM cell line (data not shown), showed similar results, and performed in triplicate. 
Ku86v to DNA was constitutively greater in the cytosol and cell membrane, but not in the nucleus (Fig. 2B, band position II); suggesting that $69-\mathrm{kDa}$ Ku $86 \mathrm{v}$ could be functionally different in different cellular compartments. Binding of DNA to 69-kDa Ku86v in both the cytosol and cell membrane is increased following CD40 triggering of RPMI 8226 MM cell lines; suggesting that CD40 triggering could induce the DNA-binding activity of Ku86v. This increased binding following CD40 triggering is not accompanied by increased amount of Ku86v expression in the nuclear fraction, as the levels are similar before and after CD40 triggering (Fig. 2A). Whereas this appears to be true for cell membrane $\mathrm{Ku} 86 \mathrm{v}$, expression of $69-\mathrm{kDa}$ $\mathrm{Ku} 86 \mathrm{v}$ in the cytosol is increased by approximately 2.5fold after CD40 triggering (Fig. 2A), suggesting that increased sequestration or recruitment of $69-\mathrm{kDa} \mathrm{Ku} 86 \mathrm{v}$ to the cytosol, rather than an increase in the DNA-binding activity of Ku86v, could be the more probable reason for these observations. This data is in contrast to a previously published report that shows a predominant Ku86 variant DNA-binding complex in nuclear extracts of human lymphocytes [20] and suggests that MM cells have a unique pattern of Ku86 distribution.

\section{9-kDa Ku86v in MM cell lines is not the result of alternative splicing of RNA or post-translational modification by $\mathbf{N}$-linked deglycosylation}

Since 69-kDa Ku86v in MM cell lines does not result from proteolytic cleavage during cell lysis, we asked whether the RNA transcript arose through alternative splicing. As was reported in other studies, $[5,16]$ northern blotting demonstrated only two RNA transcripts of $3.4 \mathrm{~kb}$ and 2.6 kb length in RPMI 8226 and SGH-MM5 MM; K562 (negative control); and HL-60 (positive control) cell lines (data not shown). Moreover, the larger $3.4 \mathrm{~kb}$ RNA transcript contains both the $5^{\prime}$ and 3 ' regulatory untranslated material $[24,25]$ as well as the typical translated product. These data concur with previously published data and suggest that both RNA transcription and splicing are normal in RPMI 8226 and SGH-MM5 MM cell lines. Moreover, CD40 activation did not appear to affect RNA transcription and splicing of Ku86 (data not shown). Since post-translational modifications can also generate truncated protein variants, and numerous proteins in MM cells have been found to be heavily glycosylated [26-28], we studied the post-translational carbohydrate modifications of Ku86 and Ku86v proteins in order to determine whether the $69-\mathrm{kDa} \mathrm{Ku} 86 \mathrm{v}$ is the result of post-translational degycosylation. As can be seen in Fig. 3A, neither short term ( 2 hrs) nor long term ( 24 hrs) EndoH treatment resulted in a decrease of $69-\mathrm{kDa}$ Ku86v and concomitant increase of 86-kDa Ku86; suggesting that truncated Ku86v was not the result of N-linked deglycosylation of the 86$\mathrm{kDa} \mathrm{Ku} 86$ [29]. By contrast, EndoH treatment induced a faster migrating form of the $44-\mathrm{kDa}$ heavy chain of the human (MHC) class I protein (Fig. 3B), which is known to be heavily glycosylated in the endoplasmic reticuculum [30,31].

\section{Proteolysis plays an important role in the intracellular generation of 69-kDa Ku86v in MM cell lines}

In order to investigate other post-translational modifications that might be responsible for the generation of 69$\mathrm{kDa} \mathrm{Ku} 86 \mathrm{v}$, we looked at the intracellular proteolytic degradation of Ku86. Since our current data (Fig. 1B and 2A) have demonstrated that various in vitro protease inhibition strategies using fresh cell lysates did not reduce the generation of 69-kDa Ku86v, we investigated the effects of various inhibitors in whole MM cells. Within the MM cell, the ubiquitin-proteasome pathway is amongst the most active intracellular protein degradation systems. Surprisingly, incubation of whole MM cells with 2 to $24 \mathrm{ng} / \mathrm{mL}$ of bortezomib (Velcade ${ }^{\circledast}$, Millennium Pharmaceuticals, MA, USA), a proteasome inhibitor, for as much as $48 \mathrm{hrs,}$ had no effect on proteolytic generation of Ku86 or Ku86v (data not shown); suggesting that other proteolytic systems could be active in the MM cell. However, simultaneous inhibition of several classes of proteases; namely serine, cysteine and metallo- proteases using Complete ${ }^{\mathrm{TM}}$ tablets for 18 hrs was associated with 3- to 7-fold decreased expression of 69-kDa Ku86v (Fig. 4A lanes 2 and 3 ), as compared to the mock experiment (Fig. 4A lane 1 ). The data again suggest that $69-\mathrm{kDa} \mathrm{Ku} 86 \mathrm{v}$ is generated constitutively within living MM cells. Similarly, broadbased inhibition of serine proteases via aprotinin plus PMSF (Fig. 4B lane 4), but not inhibition of cysteine proteases via antipain plus leupeptin (Fig. 4B lane 3), for 24 hrs is associated with 3- to 4-fold decreased expression of 69-kDa Ku86v; further suggesting that serine proteases (but not cysteine proteases) could be involved in generation of $69-\mathrm{kDa}$ Ku86v. Importantly, protease inhibition did not affect cell viability (data not shown), or expression of $86-\mathrm{kDa}$ Ku 86 or actin. These data are consistent with a report that suggests that nuclear serine proteases are responsible for in vitro generated forms the Ku86 variant [22].

\section{Trypsin generates a 69-kDa Ku86 variant protein from a full-length cloned human MM Ku86 protein (rhKu86) in vitro}

In order to specifically test whether the $69-\mathrm{kDa} \mathrm{Ku} 86 \mathrm{~V}$ protein could be a result of protease digestion of fulllength $86-\mathrm{kDa}$ Ku86, we first cloned full-length human Ku 86 from MM cell lines and produced full-length recombinant human Ku86 (rhKu86) in COS cells. During the purification of the 6-histadine-tagged rhKu86 protein from COS cells complexes of around $220-\mathrm{kDa}$ were observed in the flow through and whole cell extracts, but in the eluted concentrated rhKu86 protein fraction, no higher order complexes were observed (data not shown). 

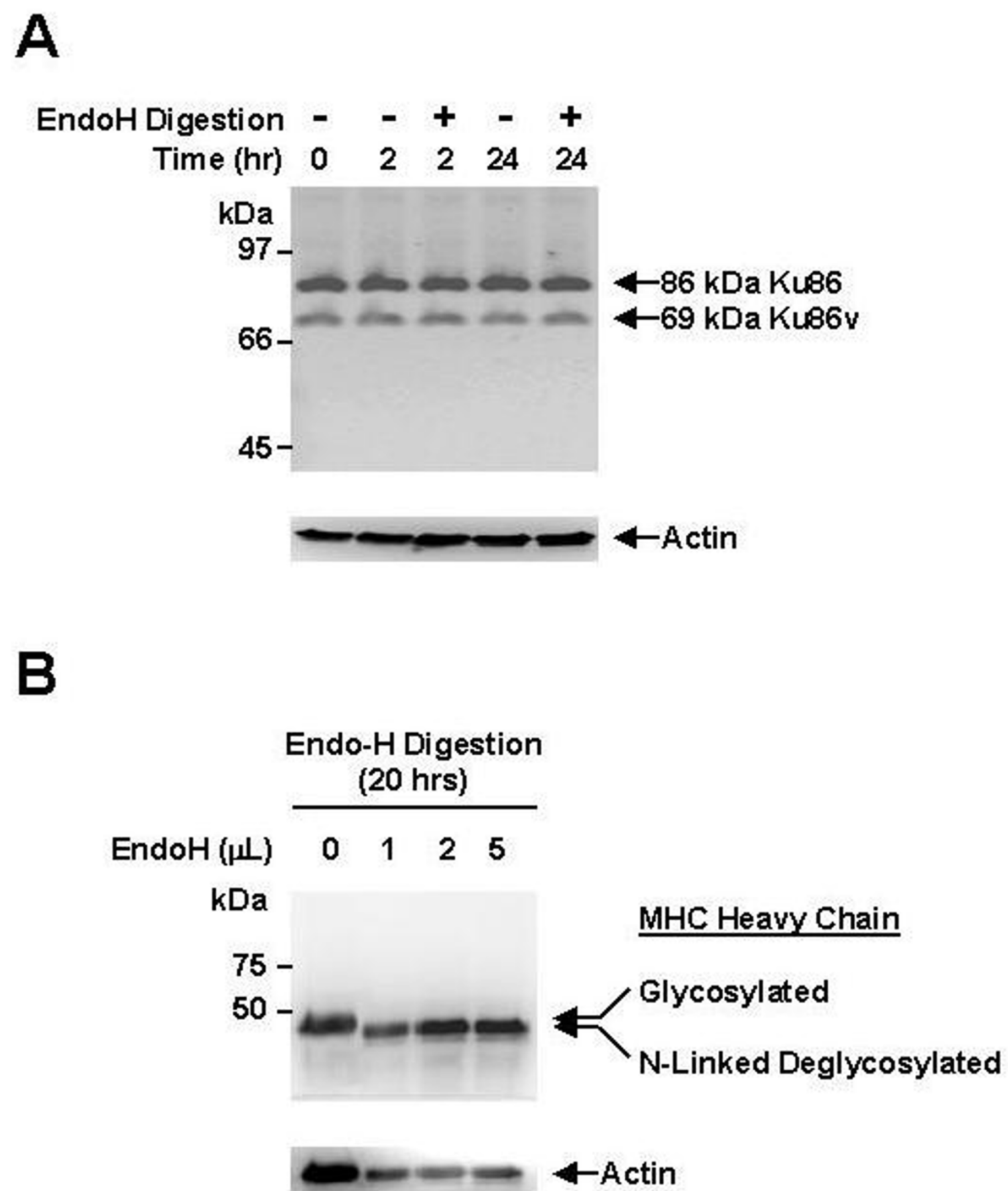

Figure 3

69-kDa Ku86v in MM cell lines is not the result of post-translational modification by $\mathbf{N}$-linked deglycosylation. Freshly obtained cell lysates $(30 \mu \mathrm{g} / \mathrm{sample})$ from the SGH-MM5 MM cell line were incubated with or without EndoH (500 U/

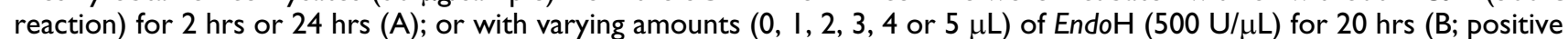
control); and then resolved in a $12.5 \%$ SDS-PAGE gel, and immunoblotted using SIOBI anti-Ku86 (A), or anti-heavy chain of the human $\mathrm{MHC}$ class I protein mAbs (B). Membranes were stripped and re-probed using anti-actin mAb (control) to confirm equal protein loading. Experiments were performed in triplicate. 
A
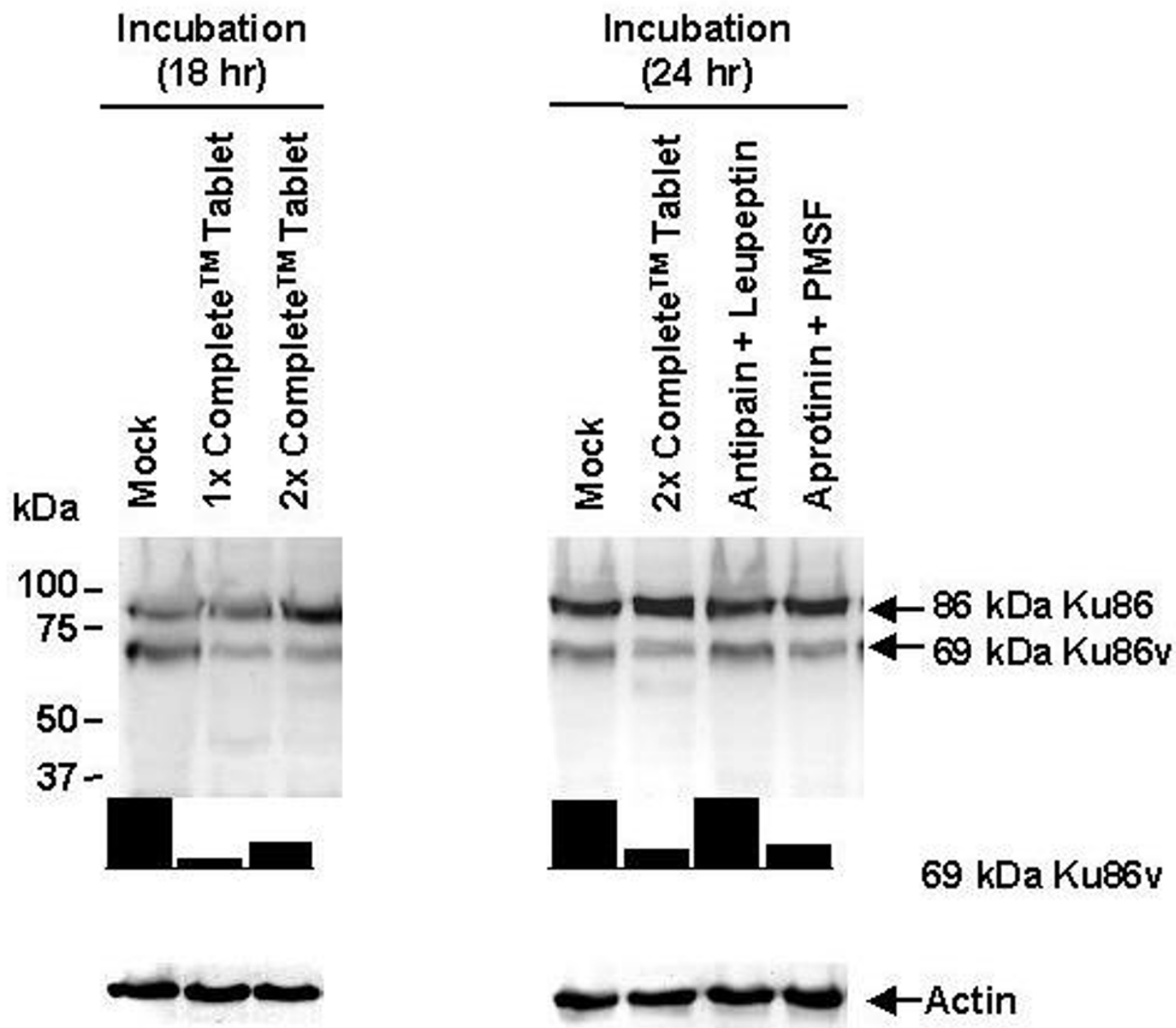

Figure 4

Proteolysis plays an important role in the intracellular generation of the 69-kDa Ku86v variant protein in MM cell lines. RPMI 8226 (A) and SGH-MM5 (data not shown) MM cell lines $\left(5.0 \times 10^{6}\right.$ cells/sample) were first incubated for 18 hrs with either $1 \times$ or $2 \times$ Complete $^{T M}$ protease inhibitor tablets (lanes 2 and 3 ); and then washed and checked for viability using trypan blue exclusion assay. Mock experiments in which cell lines were incubated for 18 hrs with media alone (lane I) served as negative controls. Cell lysates were resolved by SDS-PAGE and immunoblotted using SIOBI anti-Ku86 mAb. The RPMI 8226 $\mathrm{MM}$ cell line s (B) was also incubated for $24 \mathrm{hrs}$ with $2 \times$ Complete $^{\mathrm{TM}}$ protease inhibitor tablets (lane 2$)$, antipain $(2.0 \mu \mathrm{g} / \mathrm{mL}$ final concentration) plus leupeptin $(2.0 \mu \mathrm{g} / \mathrm{mL}$ final concentration) (lane 3$)$, or aprotinin $(2.0 \mu \mathrm{g} / \mathrm{mL}$ final concentration) plus PMSF (100 $\mu \mathrm{g} / \mathrm{mL}$ final concentration) (lane 4) and analyzed in the same way as above. Mock experiments in which cell lines were incubated for 24 hrs with media alone (lane I) again served as negative controls. Membranes were stripped and re-

probed using anti-actin mAb (control) to confirm equal protein loading. Cell lysates were resolved by SDS-PAGE and immunoblotted using SIOBI anti-Ku86 mAb. Relative expression of 69-kDa Ku86v-DNA complexes (normalized to weakest band) was determined using image densitometry. All experiments were performed in triplicate. 
This suggests that most of the Ku86 protein does not associate with monkey Ku70 and is likely due to the large excess of cloned human Ku86 to that of the endogenous monkey Ku70 proteins. Thus, this synthetic protein is likely to exist as homodimer, lacks stabilization by its usual molecular partner, Ku70, and probably undergoes some spontaneous degradation in this expression system (Fig. 5A lane 1). As can be seen in Fig. 5A lane 2, trypsin digestion rapidly (within the first minute) reduced the amount of $86-\mathrm{kDa}$ rhKu86 and increased the proportion of a $69-\mathrm{kDa}$ Ku 86 fragment. By the third minute (Fig. 5A lane 3) other smaller fragments of Ku86 have also appeared. Digestion continues over several mins, and by 20 mins., almost the entire original $86-\mathrm{kDa}$ rhKu86 as well as the $69-\mathrm{kDa}$ proteins have been digested (Fig. 5A lanes $4-7)$. These data suggest that trypsin-like proteases could preferentially generate a $69-\mathrm{kDa}$ fragment of Ku86 protein. Accordingly, to determine if protease inhibitors could now inhibit the generation of this protein, we performed trypsin digestion of rhKu86 without (Fig. 5B lane 1) or with (Fig. 5B lane 2) protease inhibitors (aprotinin plus PMSF). We demonstrate that protease inhibition is very effective in inhibiting breakdown of $86-\mathrm{kDa}$ rhKu86; but as expected, protease inhibition is not complete and some smaller fragments are formed. However, the further degradation of Ku86 is virtually inhibited. These data confirm that trypsin-like activity is likely to contribute (at least in part) to the degradation of Ku86 into a $69-\mathrm{kDa}$ variant form.

\section{Conclusion}

Karyotypic analysis of tumor cells from patients with $\mathrm{MM}$, as well as MM cell lines, frequently demonstrates numerous complex chromosomal abnormalities. Moreover, new chromosomal translocations into the switch region of the immunoglobulin heavy chain $(\mathrm{IgH})$ gene (chromosome 14q32) often heralds transformation to more aggressive MM [23] Since DNA DSBR is important in mediating these processes, this suggests that abnormalities in DSBR could ultimately lead to genomic instability, clonal evolution and disease progression in MM. Truncated variants of Ku86 protein (i.e. Ku86v) have previously been detected in $86 \%$ to $100 \%$ of freshly isolated patient MM cells [5]. However, since the expression of an altered form of the Ku86 protein in B cells [16] has been recently challenged [21]. as perhaps being non-physiological, we carefully investigated the presence of truncated forms of Ku86. The presence of the 69-kDa truncated form of Ku86 detected by antibodies directed against the $\mathrm{N}$-terminus part of the protein was confirmed in both traditional western blots as well as direct lysate fresh whole cell western immunoblotting.

In agreement with previously published data that the Cterminus truncated Ku86 variant from MM cells binds double stranded DNA ends [5], we show DNA end-binding (DEB) activity with both the full-length and truncated variant of Ku86 in all cellular subfractions tested. This is consistent with the $69-\mathrm{kDa}$ variant of Ku86 that was found in mammalian mitochondria that still associates with DNA and is found in a complex with Ku70 [19]. Since the DNA binding motifs of Ku86 are located in the $\mathrm{N}$-terminus, and the functional domains are located in the C-terminus, these data support the notion that while Ku86v-C binds DNA, it is in fact incapable of regulating DNA repair. This is further supported by published data that demonstrated the heteroduplex of Ku70 and Ku86 variant bind DNA-PKcs less well than those containing full-length Ku86 [5] and are deficient in DNA-PK activity [16]. The link between the defective DNA-PK activity as a result of Ku86 variant and Ku70 heteroduplex formation and genomic instability in MM has not been proven thus far, although cells expressing Ku86 variants do display increased sensitivity to DNA damage $[5,16,17]$. The ability of multiple myeloma-specific Ku86 variant protein to bind Ku70 or itself and to activate DNA-PK and its overall effect on DNA repair in MM cells is the subject of ongoing work.

Since protease digestion of DNA-PK and $\mathrm{Ku}$ proteins are enhanced by proteasome inhibition (i.e. bortezomib treatment) in MM cell lines [32] these data taken in aggregate further suggest that proteolytic enzymes that are capable of digesting $\mathrm{Ku}$ proteins are constitutively activated, and possibly accumulate and/or become further activated under proteasome inhibition in MM cells. Thus, the observed trypsin-like serine protease-dependent cleavage of Ku86 during the isolation procedures [22] may in fact operate naturally in intact MM cells. These findings, as well as those that found that modification of Ku86 can occur with viral infections, phorbyl ester, and calcium phosphate treatment in CV1 cells [33], suggest that under certain conditions or in certain cells lines Ku86 truncation may occur in a non-inducible proteolytic-dependent fashion. Our data suggests that these potential proteases may be acting in the cell naturally and perhaps in a constitutive fashion in MM cells. Serine protease inhibition is much more effective than cysteine protease inhibition in reducing the appearance of the Ku86 variant in whole RPMI cells (Fig. 4B). Using rhKu86 and in vitro limited digestion, one likely candidate may be trypsin (Fig. 5). In fact, by looking at the sequence of Ku86 and using bioinformatics approach we were able to narrow down potential digestion of Ku86 into 20 different proteases (using the Peptide Cutter Peptide Characterization softwareExPASy, Swiss Institute for Bioinformatics). Trypsin, chymotrypsin and other serine proteases putatively cleave Ku86 in multiple locations. However, finding the exact physiologically relevant protease that generates the variant in vivo will require more detailed analysis. We have 
only partially attempted to address this by using protease inhibitor in living cells. At the doses used, antipain and leupeptin are more selective towards cysteine inhibition than towards inhibition of serine proteases and aprotinin and PMSF are powerful serine protease inhibitors. However, it is important to note that there is likely to be some cross-inhibition. Thus, other studies using various single and multiple cysteine and serine protease inhibitors as well as mettaloproteinase inhibitors such as TIMP-2, will be needed to more closely address this issue. However, this study as well as two others, [18,22] suggest that serine proteases are likely to be important for the generation of the 69-kDa form of Ku86. However, our studies as well as others investigate Ku86 and its variant in conditions that do not allow for the association with Ku70. It is well known that Ku86 is most effective in binding DNA and recruiting DNA repair enzymes when it is heterodimerized with Ku70 which occurs via the C-terminus of both proteins [34]. We are interested in determining the naturally occurring proteolytic cleavage site of Ku86 and to examine how it affects hetero-complex formation. We hypothesize that a fraction of newly synthesized Ku86 protein is immediately and constitutively cleaved by pro- teases into a Ku86 69-kDa form that would prevent it from tight association with $\mathrm{Ku} 70$.

The localization of Ku86 within different compartments within the cell is likely to be of significant importance in $B$ cell DNA repair and perhaps in the regulation of genomic stability of $\mathrm{MM}$ cells. In fact, the intracellular trafficking of $\mathrm{Ku}$ protein to extranuclear sites has been suggested to play important role in numerous non-DNA repair Ku-associated functions [7,13] Importantly, the localization of $\mathrm{Ku}$ to the membranes of MM cells following sCD40L treatment leads to increased adhesion to bone marrow stromal cells and interneukin-6 (IL-6) production [12]. These and other studies prompted us to thoroughly examine the localization of Ku86 and Ku86 variant in the nucleus, cytosol and membrane of MM cells before and after CD40 stimulation. Unexpectedly, there were little differences observed in each of the cellular fractions for the full-length Ku86 protein levels in MM cells. Contrary to previously published data that shows increased Ku86 truncation variant in the nuclear fraction of human PBMC [22], we found equal levels of the Ku86v in the membrane, nuclear and cytosolic fractions in
A

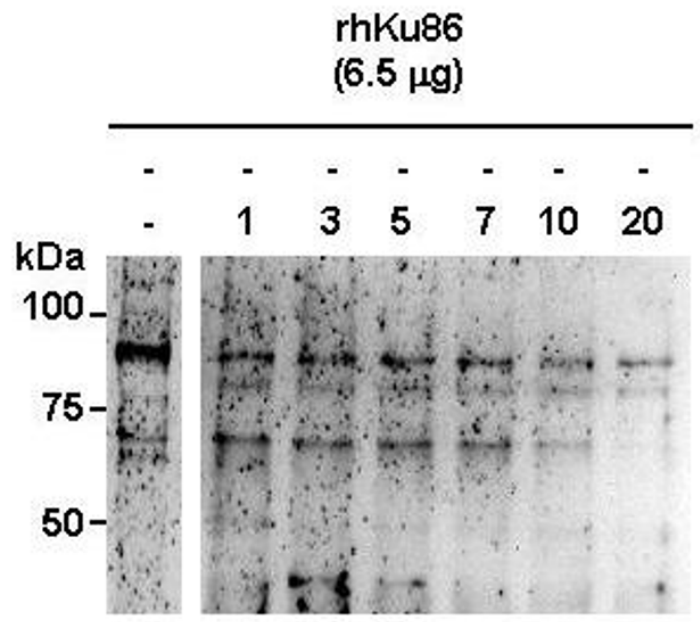

B

\section{rhKu86}

$(13.0 \mu \mathrm{g})$

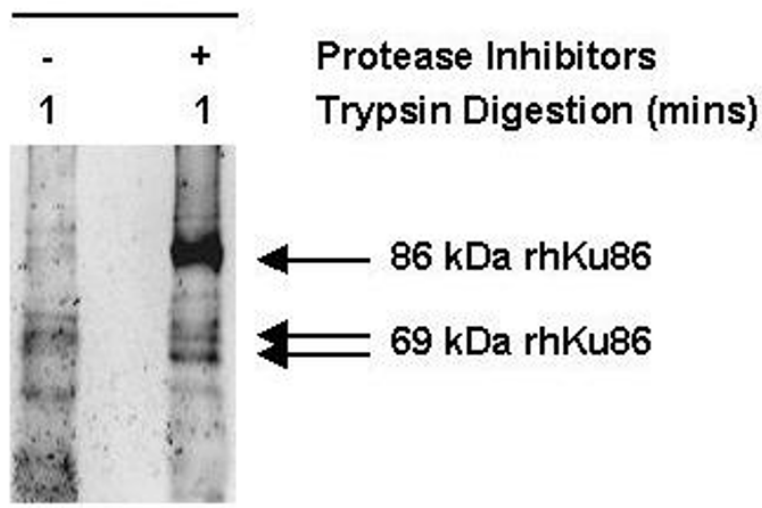

Figure 5

Trypsin digestion generates a 69-kDa Ku86 protein from a full-length cloned human MM Ku86 protein

(rhKu86) in vitro. Full-length rhKu86 was first expressed and purified from COS cells. Serial digestion (A) of rhKu86 (6.5 $\mu g /$ sample) by trypsin ( $0.065 \mu \mathrm{g}$ of Trypsin Gold/reaction up to $20 \mathrm{mins})$ was then performed using a limited proteolysis protocol from the manufacturer. The reactions were stopped by rapid cooling on ice; and the products of trypsin digestion were resolved by SDS PAGE and immunoblotted SIOBI anti-Ku $86 \mathrm{mAb}$. The effect of protease inhibitors aprotinin $(2.0 \mu \mathrm{g} / \mathrm{mL}$ final concentration) plus PMSF ( $100 \mu \mathrm{g} / \mathrm{mL}$ final concentration) on trypsin digestion was also determined on a larger sample of rhKu86 (I $3.0 \mu \mathrm{g} / \mathrm{sample})$. Trypsin digestion ( $0.065 \mu \mathrm{g}$ of Trypsin Gold/reaction for I min) of rhKu86 was performed as above either without (lane I) or with (lane 2 ) protease inhibitors (B). 
unstimulated MM cells. Yet, when the cells were stimulated with sCD40L, we did observe an increased amount of Ku86 variant in the cytosol accompanied by an increase in the DNA binding activity of Ku86v in the cytoplasm and not in the nucleus. These findings may be due to the cell type or to the fact that there appears to be little to no in vitro generated protease cleavage of Ku86 occurring during our biochemical preparations. However, the nature of the truncation is still unknown and unlikely due to posttranscriptional modification or carbohydrate modification. We are currently using more sensitive techniques of isolating various cellular fraction, performing 2-dimensional gel electrophoresis, and mass spectrometry, as well as Edmund degradation to try and determine the exact nature of this MM-specific Ku86 truncation variant. We are also currently performing studies to determine the biological function of the variant and how it might interact or disrupt the normal Ku86/Ku70/DNA-PKcs holoenzyme. Finally, we routinely see both the full-length and the truncation variant in all of our cell fractions and have not seen a time-dependent reduction in the amount of full-length Ku86 nor an increase in the variant Ku86 under any conditions. We therefore believe that the variant seen in MM cell lines is regulated in a distinct fashion from the Ku86 truncation variant that is seen in PBMCs.

\section{Abbreviations}

CSR: Class switch recombination; DNA-PKcs: DNAdependent Protein Kinase catalytic subunit; DSBR: DNA Double Stranded Break Repair; Endo H: Endonuclease H; MM: Multiple Myeloma; NHEJ: Non Homologous End Joining.

\section{Competing interests}

The authors declare that they have no competing interests.

\section{Authors' contributions}

FG and GC performed all of the molecular and biochemical experiments in this manuscript. CG and GT conceived of the study, and participated in its design and coordination and helped to draft the manuscript. All authors read and approved the final manuscript.

\section{Acknowledgements}

This work was supported by research grants from the National Medical Research Council (NMRC), Singapore (grant \#s NMRC/0489/2000 and NMRC/0734/2003); SingHealth (SUI06/2004); the Department of Clinical Research, SGH; and the Singapore Cancer Syndicate (grant \# SCS TS0026).

\section{References}

I. Nussenzweig A, Chen C, da CS V, Sanchez M, Sokol K, Nussenzweig MC, Li GC: Requirement for Ku80 in growth and immunoglobulin V(D)J recombination. Nature 1996, 382:55 I-555.

2. Lieber MR, Grawunder U, Wu X, Yaneva M: Tying loose ends: roles of Ku and DNA-dependent protein kinase in the repair of double-strand breaks. Curr Opin Genet Dev 1997, 7:99-104.

3. Muller C, Calsou P, Frit P, Cayrol C, Carter T, Salles B: UV sensitivity and impaired nucleotide excision repair in DNA-depend- ent protein kinase mutant cells. Nucleic Acids Res 1998, 26:1382-1389.

4. Salles B, Calsou P, Frit P, Muller C: The DNA repair complex DNA-PK, a pharmacological target in cancer chemotherapy and radiotherapy. Pathol Biol (Paris) 2006, 54: I85- 193.

5. Tai YT, Teoh G, Lin B, Davies FE, Chauhan D, Treon SP, Raje N, Hideshima T, Shima Y, Podar K, Anderson KC: Ku86 variant expression and function in multiple myeloma cells is associated with increased sensitivity to DNA damage. J Immunol 2000, 165:6347-6355.

6. Tai YT, Podar K, Kraeft SK, Wang F, Young G, Lin B, Gupta D, Chen LB, Anderson KC: Translocation of Ku86/Ku70 to the multiple myeloma cell membrane: functional implications. Exp Hematol 2002, 30:212-220.

7. Gullo C, Au M, Feng G, Teoh G: The biology of Ku and its potential oncogenic role in cancer. Biochim Biophys Acta 2006, 1756:223-234.

8. Tuteja R, Tuteja N: Ku autoantigen: a multifunctional DNAbinding protein. Crit Rev Biochem Mol Biol 2000, 35: I-33.

9. Bakalkin G, Yakovleva T, Hurd YL, Nussenzweig A, Li GC, Terenius $\mathrm{L}$ : Autoantigen $\mathrm{Ku}$ in the brain. Developmentally regulated expression and subcellular localization. Neuroreport 1998, 9:2|47-2|5|.

10. Dalziel RG, Mendelson SC, Quinn JP: The nuclear autoimmune antigen $\mathrm{Ku}$ is also present on the cell surface. Autoimmunity 1992, | 3:265-267.

II. Prabhakar BS, Allaway GP, Srinivasappa J, Notkins AL: Cell surface expression of the 70-kD component of $\mathrm{Ku}$, a DNA-binding nuclear autoantigen. J Clin Invest 1990, 86: I 30 I-I 305.

12. Teoh G, Urashima M, Greenfield EA, Nguyen KA, Lee JF, Chauhan D, Ogata A, Treon SP, Anderson KC: The 86-kD subunit of $\mathbf{K u}$ autoantigen mediates homotypic and heterotypic adhesion of multiple myeloma cells. J Clin Invest 1998, I0 I: I 379-1388.

13. Koike M, Awaji T, Kataoka M, Tsujimoto G, Kartasova T, Koike A, Shiomi T: Differential subcellular localization of DNA-dependent protein kinase components $\mathrm{Ku}$ and DNA-PKcs during mitosis. J Cell Sci 1999, I I 2 ( Pt 22):403I-4039.

14. Koike M, Ikuta T, Miyasaka T, Shiomi T: Ku80 can translocate to the nucleus independent of the translocation of Ku70 using its own nuclear localization signal. Oncogene 1999, 18:7495-7505.

15. Tovari J, Szende B, Bocsi J, Falaschi A, Simoncsits A, Pongor S, Erchegyi J, Stetak $A$, Keri G: $A$ somatostatin analogue induces translocation of $\mathrm{Ku} 86$ autoantigen from the cytosol to the nucleus in colon tumour cells. Cell Signal 1998, 10:277-282.

16. Muller C, Dusseau C, Calsou P, Salles B: Human normal peripheral blood B-lymphocytes are deficient in DNA-dependent protein kinase activity due to the expression of a variant form of the Ku86 protein. Oncogene 1998, 16:1553-1560.

17. Han Z, Johnston C, Reeves WH, Carter T, Wyche JH, Hendrickson EA: Characterization of a Ku86 variant protein that results in altered DNA binding and diminished DNA-dependent protein kinase activity. J Biol Chem 1996, 27 I: | 4098-I4I04.

18. Jeng YW, Chao HC, Chiu CF, Chou WG: Senescent human fibroblasts have elevated Ku86 proteolytic cleavage activity. Mutat Res 1999, 435:225-232.

19. Coffey G, Campbell C: An alternate form of Ku80 is required for DNA end-binding activity in mammalian mitochondria. Nucleic Acids Res 2000, 28:3793-3800.

20. Lanuszewska J, Widlak P: The truncation of Ku86 in human lymphocytes. Cancer Lett 2004, 205:197-205.

21. Sallmyr A, Henriksson G, Fukushima S, Bredberg A: Ku protein in human $T$ and $B$ lymphocytes: full length functional form and signs of degradation. Biochim Biophys Acta 200I, 1538:305-3/2.

22. Sallmyr A, Du L, Bredberg A: An inducible Ku86-degrading serine protease in human cells. Biochim Biophys Acta 2002, 1593:57-68.

23. Hwang WY, Gullo CA, Shen J, Poh CK, Tham SC, Cow G, Au M, Chan EW, Teoh G: Decoupling of normal CD40/interleukin-4 immunoglobulin heavy chain switch signal leads to genomic instability in SGH-MM5 and RPMI 8226 multiple myeloma cell lines. Leukemia 2006, 20.:7।5-723.

24. Cai QQ, Plet A, Imbert J, Lafage-Pochitaloff M, Cerdan C, Blanchard JM: Chromosomal location and expression of the genes coding for Ku p70 and p80 in human cell lines and normal tissues. Cytogenet Cell Genet 1994, 65:221-227. 
25. Muller C, Salles B: Regulation of DNA-dependent protein kinase activity in leukemic cells. Oncogene 1997, 15:2343-2348.

26. Belessi C, Stamatopolous K, Kosmas C: Glycosylation of $\mathbf{V}$ region genes in follicular lymphoma as a result of the somatic hypermutation mechanism. Blood 2002, 100:2269-2270.

27. Farooq M, Takahashi N, Arrol H, Drayson M, Jefferis R: Glycosylation of polyclonal and paraprotein IgG in multiple myeloma. Glycoconj J 1997, 14:489-492.

28. Nakamura F, Kaimori M, Takaya H, Fujita K, Suzuki N, Sakurabayashi I, Yoshioka N: [Markedly elevated serum fructosamine in a non-diabetic patient with IgA-kappa type multiple myeloma]. Rinsho Byori 1996, 44:85-89.

29. Gentzsch M, Cui L, Mengos A, Chang XB, Chen JH, Riordan JR: The PDZ-binding chloride channel CIC-3B localizes to the Golgi and associates with cystic fibrosis transmembrane conductance regulator-interacting PDZ proteins. J Biol Chem 2003, 278:6440-6449.

30. Parham P: Functions for MHC class I carbohydrates inside and outside the cell. Trends Biochem Sci 1996, 21:427-433.

31. van Leeuwen JE, Kearse KP: Deglucosylation of $\mathbf{N}$-linked glycans is an important step in the dissociation of calreticulin-class ITAP complexes. Proc Natl Acad Sci U S A 1996, 93:13997-1400I.

32. Mitsiades N, Mitsiades CS, Poulaki V, Chauhan D, Fanourakis G, Gu X, Bailey C, Joseph M, Libermann TA, Treon SP, Munshi NC, Richardson PG, Hideshima T, Anderson KC: Molecular sequelae of proteasome inhibition in human multiple myeloma cells. Proc Natl Acad Sci U S A 2002, 99: | 14374- 14379.

33. Quinn JP, Simpson J, Farina AR: The Ku complex is modulated in response to viral infection and other cellular changes. Biochim Biophys Acta 1992, I 13 1:181-187.

34. $\mathrm{Wu} X$, Lieber MR: Protein-protein and protein-DNA interaction regions within the DNA end-binding protein Ku70Ku86. Mol Cell Biol 1996, 16:5।86-5193.

\section{Publish with Bio Med Central and every scientist can read your work free of charge}

"BioMed Central will be the most significant development for disseminating the results of biomedical research in our lifetime. "

Sir Paul Nurse, Cancer Research UK

Your research papers will be:

- available free of charge to the entire biomedical community

- peer reviewed and published immediately upon acceptance

- cited in PubMed and archived on PubMed Central

- yours - you keep the copyright 